\title{
Perception, Preventive Practice, and Attitude Towards Vaccine Against COVID-I 9 Among Health Care Professionals in Bangladesh
}

\author{
Morshed Nasir (D) \\ Md Anisuz Zaman ${ }^{2}$ \\ Touhidul Karim Majumder ${ }^{3}$ \\ Faruque Ahmed ${ }^{3}$ \\ Rumana Nazneen ${ }^{4}$ \\ Eliza Omar (iD ${ }^{5}$ \\ Rawshan Ara Perveen (D) \\ Nadia Farha' \\ Tahmina Zahan' \\ Mir Jakib Hossain ${ }^{3}$ \\ Sultana Parvin ${ }^{3}$ \\ Moshfiqur Rahman Chowdhury ${ }^{3}$ \\ Hasina Begum ${ }^{6}$ \\ 'Department of Pharmacology, Holy \\ Family Red Crescent Medical College, \\ Dhaka, Bangladesh; ${ }^{2}$ Department of \\ Pediatric Surgery, Holy Family Red \\ Crescent Medical College Hospital, \\ Dhaka, Bangladesh; ${ }^{3}$ Department of \\ Gastroenterology, Sheikh Russel National \\ Gastro-liver Institute and Hospital, \\ Dhaka, Bangladesh; ${ }^{4}$ Department of \\ Gynecology \& Obstetrics, Holy Family \\ Red Crescent Medical College Hospital, \\ Dhaka, Bangladesh; ${ }^{5}$ Department of \\ Pharmacology, Shaheed Suhrawardy \\ Medical College, Dhaka, Bangladesh; \\ ${ }^{6}$ Department of Radiology and Imaging, \\ Sheikh Russel National Gastro-liver \\ Institute and Hospital, Dhaka, Bangladesh
}

Background: Healthcare professionals (HCPs) are one of the vital and persuading means of information, prevention and control, and incentive of vaccination to content a pandemic. Therefore, knowing the status of HCPs' perception about symptoms, transmission, preventive measures, and attitudes towards a vaccine against COVID-19 is crucial.

Methods: This multi-center cross-sectional descriptive study was one of the first and foremost ones in Bangladesh among the HCPs - doctors, nurses, and other subordinates (MLSS) engaged at COVID-dedicated hospitals. The study was conducted from February 5, 2021, to March 7, 2021, using a convenience sampling method among 550 HCPs using structured questionnaire with twenty-five questions on a three-point scale of responses.

Results: The age range of the respondents were 18 to 64 years with the mean $36.17 \pm 10.94$ years of 524 HCPs, of which the majority of the respondents were female $323(61.6 \%)$ and 201 (38.4\%) were male with the $95.27 \%$ response rate. Almost all participants had "high" or more than sufficient perception (94.34\%) about the symptoms of COVID-19. But all categories of HCPs expressed their poor or fair practice about restraining from shaking hands, and only $6.84 \%$ of nurses, $8.33 \%$ doctors, and $11.59 \%$ of MLSS avoided crowded public gatherings as a practice of prevention. A majority $(95.99 \%)$ of the HCPs showed positive attitudes about the availability of vaccines free of cost, and $87.40 \%$ showed trust in the efficacy and safety of the vaccine against COVID-19.

Conclusion: The majority of the HCPs from the COVID-dedicated hospitals have a good perception and positive attitude towards vaccination; nevertheless, have a poor practice of prevention toward COVID-19. This may play a vital role in motivation and wide acceptance of vaccine among the general population and contribute in comprehensive strategic planning to fight back against the pandemic in the country with the restricted resource.

Keywords: perception, practice, attitude, transmission, prevention, COVID-19, healthcare professionals, Bangladesh

\section{Introduction}

Nearly one and half years have passed world has fought against the COVID-19 pandemic with more than 173 million confirmed cases and 3.7 million deaths reported worldwide up to the first week of June, 2021. ${ }^{1}$ Many countries including Bangladesh fight with second wave with a new variant of coronavirus more intensely with 809,314 confirmed cases and 12,801 deaths. ${ }^{2}$ Safe and effective vaccination is the only way to reduce mortality and slow this pandemic situation, but the eradication of COVID-19 appears to be virtually impossible, however, with
Correspondence: Morshed Nasir Email morshednasir@hotmail.com; morshed@hfrcmc.edu.bd 
a great trial and efforts of researchers, based on the WHO and CDC report, understanding its clear mode of transmission and taking appropriate preventive measures are the most essential and life-saving strategies for controlling the disease. Social isolation, appropriate face mask usage, following rules of social distancing, and proper handwashing practice or sanitization are among the most frequently recommended intervention measures. However, the US Food and Drug Administration (FDA) and the European Medicines Agency (EMA) set a cutoff of $50 \%$ as the efficacy required to approve a COVID-19 vaccine. Around $67 \%$ of efficacy against the COVID-19 vaccine may be enough to slow the spread of pandemic. ${ }^{3}$ Usually, the vaccine development process is slow and needs a brief period to go through rigorous checks for potency, efficacy, and safety, particularly in human trials (phase-II and phase-IV). But the launch of the COVID-19 vaccine was an accelerated program. From the very first day of this pandemic to date 66 vaccine candidates are in the clinical trial and 20 are in Phase III trials and trials for four other candidates were reported. ${ }^{3}$ In Phase III trials, several vaccines demonstrate efficacy as high as $95 \%$ in preventing symptomatic infections. The efficacy rate ranged from $62 \%$ to $96 \%$ for different vaccine-products against COVID-19, and it took the vaccines to go to market merely nine months after the discovery of the virus. ${ }^{4}$

Healthcare professionals are at the frontline of the COVID-19 pandemic response and are more vigorously exposed in a densely populated country to threats like frequent exposure to organisms, long working hours, psychological distress, fatigue, occupational burnout, social stigma, and physical violence. A poor understanding of the disease among HCPs can result in delayed identification and treatment leading to the rapid spread of infections. Reasonably, the acceptance of the new vaccine remains uncertain by both, healthcare professionals (HCP) and the citizens at large. ${ }^{5}$ From the beginning of the COVID-19 pandemic, HCP are working in the front line, despite the higher risk of getting infected and die. They do their professional work with a fear of becoming infected not only with them but also with their patients and family members. ${ }^{6}$ Besides, HCP are the key source of information for vaccines, and their communication among patients and communities, which is a part of their professional duty, can accelerate vaccination recommendations. ${ }^{7}$ Several threats were detected according to the COVID-19 vaccine implementation, even among the HCP. ${ }^{8}$ Health professionals are more sensible in their consumption of information. HCP who worked in the front line thought that they have developed protective antibodies due to infected multiple times with the virus. ${ }^{9}$ But the longevity and effectiveness of the immune response after the vaccination remained unresolved in the RCTs. ${ }^{10}$ Above all of that, the accelerated development and approval of the COVID-19 vaccine still questionable among HCPs. Over their safety, which has an immense impact on the general public's decision. ${ }^{11-13}$ Many countries around the world have prioritized HCPs to be the first to receive the vaccine. But in several regions like Ohio state, $60 \%$ of nursinghome staff refused to take the vaccine, in New York, 30\% of HCPs turn it down. ${ }^{14,15}$

There is a paucity of literature on perception, practice and attitude of HCPs toward the COVID-19 pandemic. However, studies on South Asian HCPs and medical students revealed that they had insufficient knowledge about COVID-19 but had a positive attitude toward the prevention of transmission of the COVID-19. To our knowledge, no study has been done in Bangladesh including doctors, nurses, and MLSS (ward boy, cleaner, medical technicians) at the COVID-dedicated hospitals. Considering all those consequences and changeable perceptions of HCPs, this multi-center cross-sectional descriptive study is the first to reveal the basic perception of symptoms. Transmission, preventive measures, practice of prevention, and attitudes towards vaccine among different categories of HCPs serving in COVID-dedicated hospitals in Dhaka, Bangladesh, a low-middle income country containing the pandemic successfully in the region with limited healthcare facilities and manpower.

\section{Methods}

\section{Study Design}

This was a multi-center cross-sectional descriptive study.

\section{Setting and Subjects}

The study was carried out at Holy Family Red Crescent Medical College Hospital (HFRCMCH), a 252-bed nongovernment hospital, and Sheikh Russel National Gastroliver Institute and Hospital (SRNGIH), a 250-bed government hospital in Dhaka, Bangladesh from February 5, 2021, to March 7, 2021, using a convenience sampling method. Both the study centers were tertiary care hospitals designated as COVID-dedicated during the study period of the pandemic. Inclusion criteria: All healthcare professionals (HCPs) - doctors, nurses, and members of 
lower subordinate society (MLSS), who were serving at the study centers during the study period and consented voluntarily. Exclusion criteria: HCPs who were not regular staff at the study centers; and those who refused to participate in the study.

\section{Sample Size}

The sample size of this study was determined by applying a sample size formula to estimate a single proportion, with a confidence level (CI) of $95 \%$, the margin of error of $2 \%$, an average study population of around $630 \mathrm{HCPs}$ an estimated dropout rate of $20 \%$, resulting in at least 504 participants were necessary. However, a total of 583 HCPs agreed voluntarily and 550 completed the questionnaire, and $26 \mathrm{HCPs}$ of different categories were excluded for the pre-testing and face validation of the questionnaire and their responses were not included in the study results. As a result, the original sample size calculated in this study was 524 participants to maximize the validity, representability, and generalizability of the HCPs.

\section{Study Instrument}

Data were collected through a pre-tested and validated questionnaire developed by the authors after comprehensive reviews of the currently available published studies. The questionnaire was pre-tested for clarity, length, and face validity in two hospitals among a separate group of HCPs not included in the study. The questionnaire consisted of 4 main parts: (1) Socio-demographic data (2) Perception about symptoms, transmission, and prevention of COVID-19 (3) Practice towards COVID-19 prevention, and (4) Attitude towards vaccination against COVID-19. The first part of the survey investigated socio-demographic-related information on the HCPs. The second part of the questionnaire examined the respondents' perception, which was defined by three sub-components, namely symptoms, transmission, and prevention of COVID-19 precautionary measures. There were 15 true/false/do not know questions to gather information about the respondent's level of perception. Each item was counted as +1 if the respondents chose the correct answer and 0 for the unsure answer, and -1 for the wrong answer giving it a total score of -15 to +15 . The perception was defined as "wrong" if the total score was -15 to 0 , "low" or insufficient if the score was 0 to 9 points, corresponding to less than $60 \%$; "moderate" or sufficient if the total score ranged 10-12 (60-80\%); and "high" if the total score was 12 to $15(80-100 \%)$. In section three, 5 questions with always/sometimes/never were employed to measure
HCPs' practice of prevention. The correct answer received $\mathrm{a}+1$ point while the wrong one received -1 , resulting in a total score ranging from -5 to +5 . The practice was determined to categorize as "poor" if the total score was -5 to 0 , "fair" if the score was 1 to 3 , corresponding up to $60 \%$ correct responses, and "good" if the total score was 4 to 5 , corresponding to more than $80 \%$ correct response of preventive practices. The fourth part of the questionnaire with 5 questions on attitude towards vaccination with true/ false/do not know were employed to measure HCPs' attitude towards vaccination. The correct answer received +1 point whiles the wrong one received -1 , resulting in a total score ranging from -5 to +5 . The Attitude was determined to categorize as "negative" if the total score was -5 to 0 , "neutral" if the score was 1 to $2(20-50 \%)$, and "positive if the total score was 3 to 5 corresponding to more than $60 \%$ correct responses.

The first draft version of the questionnaire was sent to three experts in medicine, public health, and epidemiology to evaluate the internal consistency of the sections and check on their clarity, validity, and acceptable reliability. Then, 26 potential respondents from different categories were asked for their opinion as the questionnaire was translated into the local language (Bengali) for better understanding.

\section{Data Collection}

All the eligible HCPs at HFRCMCH and SRNGIH centers were reached and informed about the research purpose and other relevant information to obtain their informed consent and enrolled voluntarily in the study.

\section{Data Analysis}

Collected data were organized and analyzed using SPSS Statistics for Windows, version 23.0. The mean, standard deviation (SD), frequency, and proportion were used to display demographic characteristics. Meanwhile, statistically significant differences in perception, practice, and attitude towards vaccination against COVID-19 were examined by post hoc test using one-way ANOVA with $\mathrm{p}<0.05$ being the value of statistical significance. Chisquire was also done to compare the frequency of correct responses to observe any differences among the categories of HCPs.

\section{Results}

Out of 630 HCPs being approached, 583 (92.53\%) voluntarily agreed and were included in the study. Then, 550 completely fulfilled questionnaires were collected and analyzed, 
Table I Demographic Characteristics of the Study Subjects According to Age and Category

\begin{tabular}{|c|c|c|c|c|c|}
\hline Age & Centers & Total $(n=524)$ & Doctor $(n=240)$ & Nurse $(n=146)$ & MLSS $(n=138)$ \\
\hline \multirow[t]{3}{*}{$0-19$} & $\operatorname{HF}(n=3 \mid 6)$ & - & - & - & \\
\hline & $S R(n=208)$ & 09 (4.33\%) & - & - & $09 / 208$ (4.33\%) \\
\hline & Total & $09(1.72 \%)$ & - & - & $09 / 524$ (1.72\%) \\
\hline \multirow[t]{3}{*}{$20-39$} & $H F(n=316)$ & 150 (47.47\%) & $1|7 /| 87$ (62.57\%) & $12 / 72(16.67 \%)$ & $21 / 57$ (36.84\%) \\
\hline & $S R(n=208)$ & 170 (8I.73\%) & $31 / 53(58.49 \%)$ & $71 / 74$ (95.94\%) & $68 / 81$ (83.95\%) \\
\hline & Total & $320(61.07 \%)$ & $148 / 240$ (6I.66\%) & $83 / 146$ (56.85\%) & $89 / 138$ (64.49\%) \\
\hline \multirow[t]{3}{*}{$40-59$} & $H F(n=316)$ & 159 (50.3 I\%) & $64 / 187$ (34.2\%) & $59 / 72$ (81.94\%) & $36 / 57(63.16 \%)$ \\
\hline & $S R(n=208)$ & 29 (13.94\%) & $22 / 53(41.51 \%)$ & $03 / 74(4.05 \%)$ & 04/8I (4.94\%) \\
\hline & Total & 188 (35.88\%) & $86 / 240$ (35.83\%) & $62 / 146(42.46 \%)$ & $40 / 138$ (28.98\%) \\
\hline \multirow[t]{3}{*}{$>60$} & $\operatorname{HF}(n=3 \mid 6)$ & $07(2.21 \%)$ & $06 / 187(3.21 \%)$ & $01 / 72$ (I.39\%) & - \\
\hline & $S R(n=208)$ & - & - & - & - \\
\hline & Total & 07 (1.33\%) & $06 / 240(2.5 \%)$ & $01 / 146(0.68 \%)$ & - \\
\hline \multirow[t]{3}{*}{ Male: Female } & $\operatorname{HF}(n=316)$ & II8: 198 (I:I.67) & 75: II (I:I.49) & $03: 69(1: 23)$ & $40: 17(1: 0.42)$ \\
\hline & $S R(n=208)$ & 86: 122 (I:I.4I) & 36: 17 (1:0.47) & $03: 71$ (1:23.66) & 47: 34 (I:0.72) \\
\hline & Total & 204: 320 (I:I.33) & III: 129 (I:I.6I) & 06: $140(1: 23.3)$ & 87: $5 \mathrm{I}$ (I: 0.58) \\
\hline
\end{tabular}

equivalent to an overall response proportion of $95.27 \%$. Thirty-three respondents did not complete the questionnaire or inappropriate responses and 26 respondents were excluded for the pre-testing and face validation. The age range of the respondents was 18 to 64 years with the mean $36.17 \pm 10.94$ years. Table 1 shows the demographic information of 524 HCPs, of which $316(60.3 \%)$ respondents were from the HF-center and 208 (39.7\%) from the SRcenter. The majority of the respondents were female 323 $(61.6 \%)$ and 201 (38.4\%) were male.

\section{Perception About COVID-19}

Table 2 shows the findings on the respondents' perception of COVID-19. Almost all participants had "high" or more than sufficient perception (94.34\%) about the symptoms of COVID-19. Additionally, there was a low proportion of responses with "moderate" or just sufficient perception $(80.49 \%)$ about the transmission of disease, but "high" perception (89.34\%) about prevention of the disease, respectively. Out of 15 items measuring the perception of the participants, almost all statements had their correct response rate of more than $88 \%$ about symptoms, more than $79 \%$ about transmission, and more than $86 \%$ about prevention. In contrast, only $44.66 \%$ could give a correct response when being asked "Contact or ingestion of wild animals may cause transmission of COVID-19" and $70.80 \%$ to the "General medical mask can protect from COVID-19". There were no significant differences in the rate of correct responses among different categories of HCPs.

\section{Practice of Prevention}

Table 3 shows the results regarding the patients' practices towards COVID-19 preventive action. This section had overall good practice $(69.65 \%)$ and most of the respondents $(93.88 \%)$ used protective mask whenever went out of home or attended COVID-19 patients. But all categories of HCPs expressed their poor or fair practice about restraining from shaking hands, and only $6.84 \%$ of nurses, $8.33 \%$ doctors, and $11.59 \%$ of MLSS avoided crowded public gatherings as a practice of prevention.

\section{Attitude Towards Vaccination}

The attitudes of participants towards vaccination against COVID-19 are presented in Table 4, the majority (95.99\%) HCPs showed positive attitudes about availability of vaccine free of cost, and $87.40 \%$ showed trust in the efficacy and safety of the vaccine against COVID-19. Again almost half of the respondents from the MLSS category (56.52\%) showed uncertainty on COVID-19 vaccine's efficacy and safety because of emergency development within pandemic, and $52.17 \%$ of respondents preferred natural immunity by 
Table 2 Frequency Distribution of Correct Responses of HCPs on Perception Towards COVID-I9

\begin{tabular}{|c|c|c|c|c|c|c|}
\hline \multicolumn{2}{|c|}{ Questions on Perception } & \multirow{2}{*}{$\begin{array}{l}\begin{array}{l}\text { Doctors } \\
(\mathbf{n}=\mathbf{2 4 0})\end{array} \\
232(96.67 \%)\end{array}$} & \multirow{2}{*}{$\begin{array}{l}\begin{array}{l}\text { Nurses } \\
(n=146)\end{array} \\
144(98.63 \%)\end{array}$} & \multirow{2}{*}{$\begin{array}{l}\begin{array}{l}\text { MLSS } \\
(n=138)\end{array} \\
136(98.55 \%)\end{array}$} & \multirow{2}{*}{$\begin{array}{l}\begin{array}{l}\text { Total } \\
(\mathbf{5 2 4})\end{array} \\
512(97.71 \%)\end{array}$} & \multirow{3}{*}{$\begin{array}{l}p \text {-value } \\
X^{2}=1.3152\end{array}$} \\
\hline Symptoms & Cough & & & & & \\
\hline & Fever & $238(99.16 \%)$ & $146(100 \%)$ & $134(97.10 \%)$ & $518(98.85 \%)$ & \\
\hline & Sore throat & $234(97.50 \%)$ & 140 (95.89\%) & $133(96.38 \%)$ & 507 (96.75\%) & $p=0.999936$ \\
\hline & Diarrhea & $201(83.75 \%)$ & $134(91.78 \%)$ & $129(93.48 \%)$ & $464(88.55 \%)$ & \\
\hline & Myalgia & $208(86.66 \%)$ & $138(94.52 \%)$ & 125 (90.58\%) & $47 \mid(89.88 \%)$ & \\
\hline \multirow[t]{5}{*}{ Transmission } & $\begin{array}{l}\text { COVID-19 has no specific remedy, symptomatic treatment can } \\
\text { cure most of the cases }\end{array}$ & $235(97.92 \%)$ & $139(95.21 \%)$ & $136(98.55 \%)$ & $510(97.33 \%)$ & \multirow{5}{*}{$\begin{array}{l}X^{2}=19.8358 \\
p=0.070257\end{array}$} \\
\hline & $\begin{array}{l}\text { All patients do not get critical, only the elderly suffering from co- } \\
\text { morbidities may become serious }\end{array}$ & $203(84.58 \%)$ & $117(80.14 \%)$ & $132(95.65 \%)$ & $452(86.26 \%)$ & \\
\hline & $\begin{array}{l}\text { Contact or ingestion of wild animals may cause transmission of } \\
\text { COVID-19 }\end{array}$ & 121 (50.42\%) & 71 (48.63\%) & $42(30.43 \%)$ & $234(44.66 \%)$ & \\
\hline & COVID-19 patients cannot spread the virus if no fever is present & $221(92.08 \%)$ & $117(80.14 \%)$ & $80(57.97 \%)$ & $418(79.77 \%)$ & \\
\hline & $\begin{array}{l}\text { The virus can be spread through droplets and sneezing of the } \\
\text { infected person }\end{array}$ & $230(95.83 \%)$ & 137 (93.83\%) & $128(92.75 \%)$ & $495(94.46 \%)$ & \\
\hline \multirow[t]{5}{*}{ Prevention } & Children and young adults do not require any preventive measure & $228(95 \%)$ & $130(89.04 \%)$ & $97(70.29 \%)$ & $455(86.83 \%)$ & \multirow{5}{*}{$\begin{array}{l}x^{2}=7.7329 \\
p=0.805642^{\text {ns }}\end{array}$} \\
\hline & $\begin{array}{l}\text { Everyone needs to avoid the crowd (bus-station, public transport, } \\
\text { market) to prevent COVID-19 }\end{array}$ & $233(97.08 \%)$ & $146(100 \%)$ & $116(84.06 \%)$ & $495(94.46 \%)$ & \\
\hline & $\begin{array}{l}\text { Quarantining the infected persons will reduce the spread of the } \\
\text { COVID-19 }\end{array}$ & $238(99.17 \%)$ & I4I (96.57\%) & $126(91.30 \%)$ & 505 (96.37\%) & \\
\hline & $\begin{array}{l}\text { Person who comes in contact with COVID-19 patient have to } \\
\text { remain quarantine for } 14 \text { days }\end{array}$ & $235(97.92 \%)$ & $145(99.31 \%)$ & I35 (97.83\%) & $515(98.28 \%)$ & \\
\hline & General medical mask can protect from COVID-19 & $165(68.75 \%)$ & $99(67.8 \mathrm{I})$ & $107(77.54 \%)$ & $371(70.80 \%)$ & \\
\hline
\end{tabular}

Note: $X^{2}$ means the value of Chi Square test.

Abbreviation: NS, not significant.

Table 3 Frequency Distribution of Correct Responses of HCPs on Practice

\begin{tabular}{|c|c|c|c|c|c|c|}
\hline \multicolumn{2}{|c|}{ Questions on practice } & \multirow{2}{*}{$\begin{array}{l}\begin{array}{l}\text { Doctors } \\
(n=240)\end{array} \\
20(08.33 \%)\end{array}$} & \multirow{2}{*}{$\begin{array}{l}\begin{array}{l}\text { Nurses } \\
(n=146)\end{array} \\
10(6.84 \%)\end{array}$} & \multirow{2}{*}{$\begin{array}{l}\begin{array}{l}\text { MLSS } \\
(n=138)\end{array} \\
16(11.59 \%)\end{array}$} & \multirow{2}{*}{$\begin{array}{l}\text { Total } \\
(524)\end{array}$} & \multirow[t]{2}{*}{$p$-value } \\
\hline Practice & $\begin{array}{l}\text { Have never been in crowded public gathering } \\
\text { currently }\end{array}$ & & & & & \\
\hline & $\begin{array}{l}\text { Have used mask whenever attended any patients } \\
\text { currently }\end{array}$ & $224(93.33 \%)$ & 142 (97.26\%) & $13 \mid(94.92 \%)$ & 497 (94.85\%) & \multirow{4}{*}{$\begin{array}{l}x^{2}=18.2673 \\
p=0.10781 I^{\text {ns }}\end{array}$} \\
\hline & Have restrained from shaking hands Currently & $192(80 \%)$ & II $3(77.39 \%)$ & 91 (65.94\%) & $396(75.57 \%)$ & \\
\hline & $\begin{array}{l}\text { Have cleaned hands before and after attending every } \\
\text { patients currently }\end{array}$ & $|4|(58.75 \%)$ & $14 \mid$ (96.57\%) & II 3 (8I.88\%) & $395(75.38 \%)$ & \\
\hline & Have used mask whenever went out of the home & $222(92.50 \%)$ & |4| (96.57\%) & $128(92.75 \%)$ & $491(93.70 \%)$ & \\
\hline
\end{tabular}

Note: $X^{2}$ means the value of Chi Square test.

Abbreviation: NS, not significant. 
Table 4 Frequency Distribution of Responses of HCPs on Attitude Towards Vaccination

\begin{tabular}{|c|c|c|c|c|c|c|}
\hline \multicolumn{2}{|c|}{ Questions on Attitude } & \multirow{2}{*}{$\begin{array}{l}\begin{array}{l}\text { Doctors } \\
(n=240)\end{array} \\
203(84.58 \%)\end{array}$} & \multirow{2}{*}{$\begin{array}{l}\begin{array}{l}\text { Nurses } \\
(n=146)\end{array} \\
124(84.93 \%)\end{array}$} & \multirow{2}{*}{$\begin{array}{l}\begin{array}{l}\text { MLSS } \\
(n=\mid 38)\end{array} \\
|3|(94.92 \%)\end{array}$} & \multirow{2}{*}{$\begin{array}{l}\begin{array}{l}\text { Total } \\
(524)\end{array} \\
458(87.40 \%)\end{array}$} & \multirow[t]{2}{*}{$p$-value } \\
\hline Vaccination & $\begin{array}{l}\text { In favor of vaccine against COVID-19, because it is } \\
\text { effective and safe }\end{array}$ & & & & & \\
\hline & Vaccine against COVID-19 is available free of cost & $231(96.25 \%)$ & 142 (97.26\%) & 130 (94.20\%) & $503(95.99 \%)$ & \multirow{4}{*}{$\begin{array}{l}X^{2}=22.2356 \\
p=0.034963\end{array}$} \\
\hline & $\begin{array}{l}\text { Children do not require to get COVID-19 } \\
\text { vaccination }\end{array}$ & 79 (32.92\%) & 57 (39.04\%) & $68(49.27 \%)$ & $198(37.78 \%)$ & \\
\hline & $\begin{array}{l}\text { Do not rely on COVID-19 vaccine due to } \\
\text { emergency development during pandemic }\end{array}$ & $186(77.50 \%)$ & $104(78.23 \%)$ & $78(56.52 \%)$ & $368(70.23 \%)$ & \\
\hline & $\begin{array}{l}\text { Vaccination is not required because immunity will } \\
\text { be acquired naturally by infection }\end{array}$ & $193(80.42 \%)$ & $96(65.75 \%)$ & $72(52.17 \%)$ & $361(68.89 \%)$ & \\
\hline
\end{tabular}

Note: $X^{2}$ means the value of Chi Square test.

infection rather than vaccination for immunity. While most of the HCPs showed a neutral attitude about "children do not require to get COVID-19 vaccination". Overall only $37.78 \%$ of HCPs thought the vaccine was not required for children.

\section{Score on Sufficient Perception, Good Practice and Optimistic Attitude}

The mean score of perception (11.17) out of 15 points, practice (3.16) and attitude (2.88) out of 5 points was found significantly $(p<0.001)$ lower among the MLSS, and overall score in all three domains of the study was higher among doctors followed by nurses as shown in Table 5. Statistically highly significant differences $(p<0.001)$ were observed within the categories of HCPs comparing perception about COVID-19 between doctors versus MLSS, and nurses versus MLSS, not between doctors versus nurses. However, there were no significant differences of mean score in practice of prevention, and attitude towards vaccination among the HCPs in Table 6 with 95\% confidence interval.

\section{Discussion}

This is the foremost study of its type to assess the perception and practice towards COVID-19 and attitude towards vaccination of frontline healthcare professionals in Bangladesh, and it was performed during the second wave of the pandemic. The characteristics of participants in this study were mainly female $(61.6 \%)$ with the male: Female ratio was $1: 1.33$ and nearly half of the total respondents were doctors (45.8\%). Perception about symptoms, transmission, and prevention of COVID-19 varied across different categories of HCPs. Out of $524 \mathrm{HCPs}$, $94.34 \%$ had a high perception about symptoms of COVID-19, but moderate perception about the transmission $(80.49 \%)$ that was comparatively lower than that of previously published study from Ethiopia, ${ }^{16} \mathrm{Uganda}^{17}$ and Nigeria, ${ }^{18}$ Egypt $^{19}$ and Nepal. ${ }^{20}$ However, the perception of preventive measures was high (89.34\%) among our respondents which might be for the increment of knowledge, experience, and access to information since the first wave of COVID in the country.

The present study showed the HCPs in Bangladesh had a comprehensive and high perception or more than sufficient knowledge about symptoms of COVID-19 except for diarrhea and myalgia. The mean score of perception was high among the doctors and nurses, whereas a lower score $(11.17 \pm 2.10)$ was found among the significantly different

Table 5 Mean Scores of Knowledge, Practice and Attitude Among the HCPs

\begin{tabular}{|l|l|l|l|c|c|}
\hline Mean Scores & Doctors & Nurses & MLSS & \multicolumn{2}{|c|}{ Difference Between Groups } \\
\cline { 3 - 6 } & & & & F & $<$ \\
\hline Score of perception (15) & $12.50 \pm 2.05$ & $12.34 \pm 1.62$ & $11.17 \pm 2.10$ & 21.61 & 0.001 \\
Score of practice (5) & $3.43 \pm 1.57$ & $3.40 \pm 1.43$ & $3.16 \pm 1.35$ & 1.55 & 0.213 \\
Attitude towards vaccination (5) & $3.03 \pm 1.85$ & $3.04 \pm 1.51$ & $2.88 \pm 1.65$ & 0.44 & $<.643$ \\
Overall total score & $18.95 \pm 3.69$ & $18.78 \pm 2.84$ & $17.20 \pm 3.59$ & 12.23 & 0.001 \\
\hline
\end{tabular}

Note: Post hoc test using one-way ANOVA. 
Table 6 Comparison of Score Between the Categories of HCPs

\begin{tabular}{|c|c|c|c|c|c|c|c|}
\hline & \multirow{2}{*}{$\begin{array}{l}\text { Occupation } \\
\text { Group (I) }\end{array}$} & \multirow{2}{*}{$\begin{array}{l}\text { Occupation } \\
\text { Group (J) }\end{array}$} & \multirow{2}{*}{$\begin{array}{l}\text { Mean }(I-J) \\
\text { Difference }\end{array}$} & \multirow{2}{*}{$\begin{array}{l}\text { Std. } \\
\text { Error }\end{array}$} & \multirow[t]{2}{*}{$p$-value } & \multicolumn{2}{|c|}{$95 \% \mathrm{Cl}$} \\
\hline & & & & & & $\begin{array}{l}\text { Lower } \\
\text { Bound }\end{array}$ & $\begin{array}{l}\text { Upper } \\
\text { Bound }\end{array}$ \\
\hline \multirow[t]{6}{*}{ Score of perception } & \multirow[t]{2}{*}{ Doctor } & Nurse & 0.160 & 0.206 & 0.436 & -0.24 & 0.56 \\
\hline & & MLSS & 1.329 & 0.209 & $<0.00 I^{*}$ & 0.92 & 1.74 \\
\hline & \multirow[t]{2}{*}{ Nurse } & Doctor & -0.160 & 0.206 & 0.436 & -0.56 & 0.24 \\
\hline & & MLSS & 1.169 & 0.233 & $<0.001 *$ & 0.71 & 1.63 \\
\hline & \multirow[t]{2}{*}{ MLSS } & Doctor & -1.329 & 0.209 & $<0.001 *$ & -1.74 & -0.92 \\
\hline & & Nurse & -1.169 & 0.233 & $<0.001 *$ & -1.63 & $-0.7 \mid$ \\
\hline \multirow[t]{6}{*}{ Score of practice } & \multirow[t]{2}{*}{ Doctor } & Nurse & -0.008 & 0.180 & 0.966 & -0.36 & 0.35 \\
\hline & & MLSS & 0.157 & 0.183 & 0.392 & -0.20 & 0.52 \\
\hline & \multirow[t]{2}{*}{ Nurse } & Doctor & 0.008 & 0.180 & 0.966 & -0.35 & 0.36 \\
\hline & & MLSS & 0.164 & 0.203 & 0.419 & -0.23 & 0.56 \\
\hline & \multirow[t]{2}{*}{ MLSS } & Doctor & -0.157 & 0.183 & 0.392 & -0.52 & 0.20 \\
\hline & & Nurse & -0.164 & 0.203 & 0.419 & -0.56 & 0.23 \\
\hline \multirow{6}{*}{$\begin{array}{l}\text { Score of attitude towards } \\
\text { vaccination }\end{array}$} & \multirow[t]{2}{*}{ Doctor } & Nurse & 0.021 & 0.155 & 0.893 & -0.28 & 0.33 \\
\hline & & MLSS & 0.266 & 0.158 & 0.093 & -0.04 & 0.58 \\
\hline & \multirow[t]{2}{*}{ Nurse } & Doctor & -0.021 & 0.155 & 0.893 & -0.33 & 0.28 \\
\hline & & MLSS & 0.245 & 0.176 & 0.164 & -0.10 & 0.59 \\
\hline & \multirow[t]{2}{*}{ MLSS } & Doctor & -0.266 & 0.158 & 0.093 & -0.58 & 0.04 \\
\hline & & Nurse & -0.245 & 0.176 & 0.164 & -0.59 & 0.10 \\
\hline
\end{tabular}

Notes: *The mean difference is significant at the 0.05 level. Post hoc test using one-way ANOVA.

MLSS $(p<0.001)$ from the rest of the HCPs. Most of the respondents had low perception on a particular question about transmission 'contact or ingestion of wild animals may cause transmission of COVID-19'. Only $44.66 \%$ of the respondents could answer correctly. However, the overall perception on the transmission of the disease was good, and a higher rate of correct answers compared to the studies among HCPs in India (61\%) due to inadequate dissemination of information and misunderstanding among HCPs delayed applying preventive efforts as reported by Kumar et al. ${ }^{21}$ The perception of transmission was also reported low among the HCPs in Vietnam (67\%) that might because of the survey performed in the early period of the pandemic in Ho Chi Minh City, and more interest of HCPs in social media than official websites as reported by and Giao et al. ${ }^{22}$ In terms of perception and knowledge about prevention, more than $86 \%$ of participants presented appropriate answers on COVID-19 control and prevention. Although $70.80 \%$ of the HCPs believed that 'general medical mask can protect from COVID-19'.

The provision of information to the community about the virus, its transmission modes, and necessary protective measures played a vital role in controlling the pandemic. The practice of prevention against COVID-19 was good among $69.65 \%$ HCPs in our study. However, only $58.75 \%$ of doctors "cleaned hands before and after attending every patient" and only $65.94 \%$ of MLSS 'have restrained from shaking hands. The overall practice of prevention of the participants was higher than the studies in Ethiopia $(59.6 \%),{ }^{16}$ but much lower than the findings Uganda $(74 \%)^{17}$ and China $(89.7 \%){ }^{23}$ Washing hands, wearing a mask, social distancing as a part of good practice of 
prevention by HCPs were reportedly high in the studies from Nigeria, Nepal, and China. ${ }^{18,20,23}$ Alarmingly, all three categories of HCPs had poor practice about "avoiding crowded public gathering" ranging from nurses $6.84 \%$, doctors $8.33 \%$, and MLSS $11.59 \%$ respectively in the present study. This might be due to the lack of strict enforcement of lockdown, low transmission rate, and mortality rate reported in Bangladesh during the study period. However, the mean score of practice was similar among the different categories of HCPs and no statistical difference was observed.

This study also revealed a great proportion of participants having positive attitudes towards vaccination against COVID19. Almost $95.99 \%$ of HCPs showed positive attitudes about availability, efficacy, safety, and necessity of vaccination. Although $56.52 \%$ of MLSS "do not rely on vaccine due to emergency development during pandemic". Our study revealed the positive attitude towards acceptance of vaccine against COVID-19 and was much higher than the HCPs in France (81\%), Greece (78.5\%), Israel (78\%). ${ }^{24-26}$ This observation was similar to the findings of the Asia-pacific study conducted on 1720 healthcare workers from 6 countries: China, India, Indonesia, Singapore, Vietnam, and Bhutan. ${ }^{27}$ However, a significant difference $(p<0.034)$ in the rate of correct answers about a positive attitude towards vaccines was observed among the different categories of the HCPs in our study. But the mean score on a 5-point scale was not significant as only $37.78 \%$ of the participants believed "children do not require to get COVID-19 vaccination".

\section{Limitations}

Although COVID-19 related scientific information has gained great interest among the researchers, there is a lack of studies conducted on frontline HCPs inclusive of doctors, nurses, and support staff in COVID-dedicated hospitals, particularly in Bangladesh. Therefore, it is perplexing to find adequate literature serving as references for this type of study. The questionnaire used in this study was structured on a restricted number of relevant publications available as references, and adopted according to the understanding of the local HCPs and translated in Bengali resulting in a not quite high global standard. Additionally, information bias was inescapable due to the nature of its self-answering questionnaire.

\section{Conclusion}

The findings of the present study suggested that the majority of the HCPs participated in the study from the COVID- dedicated tertiary care hospitals have good perception about symptoms, transmission, and prevention; nevertheless, have a poor practice of prevention toward COVID19. Doctors, nurses, and MLSS were much aware of the wearing of a mask, hand washing, and social distancing, but rarely avoided crowded public gatherings. Since the limitation of crowded gathering is a critical step to prevent community transmission, maximum emphasis should be given to improve preventive measures by hospital management and the Government to safeguard the HCPs against a densely populated country with resource constraints. However, most of the frontline HCPs have a very positive attitude toward vaccination that may play a vital role in motivation and wide acceptance of vaccine among the general population for the attainment of successful nationwide vaccination program in Bangladesh despite the severity of COVID-19 in many regions around the world.

\section{Strengths}

The study was conducted on HCPs who were serving closely at the leading tertiary care hospitals dedicated to the COVID-19 management in the capital city, Dhaka, Bangladesh. The study centers were a national tertiary general hospital with a variety of patients from many regions across the country seeking medical examination and treatment for COVID-19 during the pandemic. Therefore, the respondents in this study were representative of the Bangladeshi HCPs with a nationwide network, reference, integrated with information, infection control prevention strategy, and national guideline for treatment. Moreover, the questionnaire used to collect data was structured and adopted with careful and thorough referencing from previous studies, and also guidelines by WHO and the Government of Bangladesh, to maximize the accuracy and relevance of the questionnaire to the current context of COVID-19.

\section{Ethical Approval}

The study was conducted in compliance with the Declaration of Helsinki. Ethical approval was obtained from the Institutional Ethics Review Board of Holy Family Red Crescent Medical College, and Sheikh Russel National Gastroliver Institute and Hospital; Dhaka, Bangladesh before proceeding with data collection (Approval No: IERB/34/Sur/Feb/2021/10/hf). Additionally, the participants responded to the questionnaire anonymously with no identifying information required. 


\section{Author Contributions}

All authors made a significant contribution to the work reported, whether in conception, study design, execution, acquisition of data, analysis, interpretation, or all those areas; took part in drafting, revising, or critically reviewing the article; gave final approval of the version to be published; have agreed on the journal to which the article has been submitted; and agree to be accountable for all aspects of the work.

\section{Funding}

The study was not funded by any of the governmental or non-governmental funding organizations.

\section{Disclosure}

The authors declare no conflict of interest for this work.

\section{References}

1. World Metrics. COVID-19 coronavirus outbreak: world Metrics. Available from: https://www.worldometers.k+info/coronavirus/. Accessed June 6, 2021.

2. World Metrics. COVID-19 corona virus outbreak. World Metrics. Available from: https://www.worldometers/info/coronavirus/country/ Bangladesh/. Accessed June 6, 2021.

3. ClinicalTrials.gov. SCB-2019 as COVID-19 Vaccine. United States National Library of Medicine. Available from: https://clinicaltrials. gov/ct2/show/NCT04405908. Accessed August 28, 2021

4. Press Information Bureau. Indigenous mRNA vaccine candidate supported by DBT gets Drug Controller nod to initiate Human clinical trials. pib.gov.in. Available from: https://pib.gov.in/Pressreleaseshare. aspx?PRID=1680031. Accessed January 13, 2021.

5. Bhartiya S, Kumar N, Singh T, Murugan S, Rajave S, Wadhwani M. Knowledge, attitude and practice towards COVID-19 vaccination acceptance in West India. Int $J$ Commun Med Public Health. 2021;8(3):1170-1176. doi:10.18203/2394-6040.ijcmph20210481

6. Liu Q, Luo D, Haase JE, et al. The experiences of health-care providers during the COVID-19 crisis in China: a qualitative study. Lancet Glob Health. 2020;8(6):790-798. doi:10.1016/S2214-109X (20)30204-7

7. Riccò M, Gualerzi G, Ranzieri S, Ferraro P, Bragazzi NL. Knowledge, Attitudes, Practices (KAP) of Italian Occupational Physicians towards Tick Borne Encephalitis. Trop Med Infect Dis. 2020;5(3):117. doi:10.3390/tropicalmed5030117

8. Sun S, Lin D, Operario D. Interest in COVID-19 vaccine trials participation among young adults in China: willingness, reasons for hesitancy, and demographic and psychosocial determinants. Prev Med Rep. 2021;22:101350. doi:10.1016/j.pmedr.2021.101350

9. Smith TM. Dealing with COVID-19 vaccine hesitancy among health care workers. AMA. Available from: https://www.ama-assn.org/deli vering-care/public-health/dealing-covid-19-vaccine-hesitancy-among -health-care-workers. Accessed March 4, 2021.

10. Baldo V, Reno C, Cocchio S, Fantini MP. SARS-CoV-2/COVID-19 Vaccines: the Promises and the Challenges Ahead. Vaccines. 2021;9 (1):21. doi:10.3390/vaccines 9010021

11. Gagneux-Brunon A, Detoc M, Bruel S, et al. Intention to get vaccinations against COVID-19 in French healthcare workers during the first pandemic wave: a cross-sectional survey. J Hosp Infect. 2021;108:168-173. doi:10.1016/j.jhin.2020.11.020
12. Gadoth A, Halbrook M, Martin-Blais R, et al. Cross-sectional Assessment of COVID-19 vaccine acceptance among health Care Workers in Los Angeles. Ann Intern Med. 2021;174(6):882-885. doi:10.7326/M20-7580

13. Kabamba Nzaji M, Kabamba Ngombe L, Ngoie Mwamba G, et al. Acceptability of Vaccination Against COVID-19 Among Healthcare Workers in the Democratic Republic of the Congo. Pragmat Obs Res. 2020;11:103-109. doi:10.2147/POR.S271096

14. Chewa NWS, Cheongb C, Kongb G, et al. An Asia-Pacific study on healthcare workers' perceptions of, and willingness to receive, the COVID-19 vaccination. Int $J$ Infect Dis. 2021;106:52-60. doi:10.1016/j.ijid.2021.03.069

15. Julie Wernau. Wall Street Journal. Available from: https://www.wsj. com/articles/some-health-care-workers-are-still-saying-no-to -a-covid-19-vaccine-11612089020. Accessed January 31, 2021.

16. Shibabaw T, Teferi B. Knowledge and Practice Toward Prevention of SARS-CoV-2 Among Healthcare Workers at Delghi Primary Hospital During a Massive Test Campaign in Northwest Gondar, Ethiopia: institution-Based Descriptive Cross-Sectional Survey. Infect Drug Resist. 2021;14:381-390. doi:10.2147/IDR.S289965

17. Olum R, Chekwech G, Wekha G, Nassozi DR, Bongomin F. Coronavirus Disease-2019: knowledge, Attitude, and Practices of Health Care Workers at Makerere University Teaching Hospitals, Uganda. Front Public Health. 2020;8:181. doi:10.3389/fpubh.202 0.00181

18. Ejeh FE, Saidu AS, Owoicho S, et al. Knowledge, attitude, and practice among healthcare workers towards COVID-19 outbreak in Nigeria. Heliyon. 2020;6(11):e05557. doi:10.1016/j.heliyon.2020. e05557

19. Abdel Wahed WY, Hefzy EM, Ahmed MI, Hamed NS. Assessment of Knowledge, Attitudes, and Perception of Health Care Workers Regarding COVID-19, A Cross-Sectional Study from Egypt. $J$ Community Health. 2020;45(6):1242-1251. doi:10.1007/s10900020-00882-0

20. Limbu DK, Piryani RM, Sunny AK. Healthcare workers' knowledge, attitude and practices during the COVID-19 pandemic response in a tertiary care hospital of Nepal. PLoS One. 2020;15(11):e0242126. doi:10.1371/journal.pone.0242126

21. Kumar H, Khurana MS, Charan GS, et al. Knowledge and perception of health professionals towards COVID-19. Int J Health Sci Res. 2020;10(7):123-129.

22. Huynh G, Nguyen TNH, Tran VK, Vo KN, Vo VT, Pham LA. Knowledge and attitude toward COVID-19 among healthcare workers at District 2 Hospital, Ho Chi Minh. City Asian Pac J Trop Med. 2020;13(6):260-265. doi:10.4103/1995-7645.280396

23. Zhang M, Zhou M, Tang F, et al. Knowledge, attitude, and practice regarding COVID-19 among healthcare workers in Henan, China. J Hosp Infect. 2020;105(2):183-187. doi:10.1016/j.jhin.2020.04.012

24. Papagiannis D, Rachiotis G, Malli F, et al. Acceptability of COVID-19 Vaccination among Greek Health Professionals. Vaccines (Basel). 2021;9(3):200. doi:10.3390/vaccines 9030200

25. Detoc M, Bruel S, Frappe P, Tardy B, Botelho-Nevers E, GagneuxBrunon A. Intention to participate in a COVID-19 vaccine clinical trial and to get vaccinated against COVID-19 in France during the pandemic. Vaccine. 2020;38(45):7002-7006. doi:10.1016/j.vaccine. 2 020.09.041

26. Nicholas WS, Chew CC, Kong G, et al. An Asia-Pacific study on healthcare workers' perceptions of, and willingness to receive, the COVID-19 vaccination,International. $J$ Infect Dis. 2021;106:52-60.

27. Shekhar R, Sheikh AB, Upadhyay S, et al. COVID-19 Vaccine Acceptance among Health Care Workers in the United States. Vaccines (Basel). 2021;9(2):119. doi:10.3390/vaccines9020119 


\section{Publish your work in this journal}

Infection and Drug Resistance is an international, peer-reviewed openaccess journal that focuses on the optimal treatment of infection (bacterial, fungal and viral) and the development and institution of preventive strategies to minimize the development and spread of resistance. The journal is specifically concerned with the epidemiology of antibiotic resistance and the mechanisms of resistance development and diffusion in both hospitals and the community. The manuscript management system is completely online and includes a very quick and fair peerreview system, which is all easy to use. Visit http://www.dovepress.com/ testimonials.php to read real quotes from published authors.

Submit your manuscript here: https://www.dovepress.com/infection-and-drug-resistance-journal 